\title{
ANTIOXIDATIVE AND FREE RADICAL SCAVENGING POTENTIALS OF HABENARIA PECTINATA
}

\section{CHARANJIT KAUR ${ }^{1,2}$, RAJESH KUMAR ${ }^{1,3}$, GURVINDER SINGH $^{3}$, CHANDER MOHAN $^{4 *}$}

${ }^{1}$ I. K. Gujral Punjab Technical University, Kapurthala, Punjab, India. ${ }^{2}$ Department of Pharmaceutical Chemistry, Khalsa College of Pharmacy, Amritsar, Punjab, India. ${ }^{3}$ Department of Pharmaceutical Sciences, Lovely Faculty of Applied Medical Sciences, Lovely Professional University, Phagwara, Punjab, India. ${ }^{4}$ Department of Pharmaceutical Chemistry, Rayat Bahra Institute of Pharmacy,

Hoshiarpur, Punjab, India. Email: charan_3216@yahoo.in

Received: 19 December 2019, Revised and Accepted: 09 January 2020

\section{ABSTRACT}

Objective: This study was designed to evaluate the antioxidative potential of tubers of Habenaria pectinata.

Methods: The tubers of $H$. pectinata were extracted using hexane, ethyl acetate, methanol, and water as solvents. The anti-oxidant potential of extracts was evaluated using free radical scavenging and reducing power assays. The most active methanolic extract was then fractionated into four fractions using the above-mentioned solvents.

Results: The phenol and flavonoid content was found to be maximum in the methanol extracts. All the extracts and fractions showed significant levels of antioxidant activity except hexane extract.

Conclusion: The tubers of $H$. pectinata were found to possess a significant antioxidant potential and can be explored further for isolation and preclinical investigation for the ailment of various diseased states and disorders.

Keywords: Habenaria, Antioxidant, 1,1-diphenyl-2-picrylhydrazyl.

(C) 2020 The Authors. Published by Innovare Academic Sciences Pvt Ltd. This is an open access article under the CC BY license (http://creativecommons. org/licenses/by/4. 0/) DOI: http://dx.doi.org/10.22159/ajpcr.2020.v13i3.36663

\section{INTRODUCTION}

Natural resources have always been a good source of antioxidants. Several epidemiological studies suggest that a high intake of foods rich in natural antioxidants reduces the risk of several debilitating diseased states and disorders. Moreover, these antioxidants also contribute to the preservation of foods and food products. This necessitates the exploration of bioresources for newer and older antioxidants qualitatively as well as quantitatively to meet the demands of the food industry and health management systems $[1,2]$

Habenaria pectinata belongs to the family Orchidaceae; a terrestrial plant found in forests around $1800 \mathrm{~m}$ in India, Yunnan, and Nepal [3]. The crushed leaves are reported to treat snake bites and tubers for arthritis in India [4].

Preliminary investigation involving standard phytochemical tests on the prepared extracts revealed the presence of flavonoids and phenols in this plant. Moreover, the closely related species Habenaria intermedia has been reported to be a potential source of antioxidants [5]. Hence, we decided to check the total phenolic and flavonoid compounds quantitatively along with the evaluation of antioxidant properties of various extracts and fractions of $H$. pectinata connected to the presence of phenols and flavonoids in this plant

\section{METHODS}

Plant material

The tubers of the plant $H$. pectinata were collected from Shimla and Dhanaulti Regions in August. The plant material was authenticated by Manager (Quality Control and Quality Assurance Department, Herbal Health Research Consortium Pvt. Ltd., established by National Medicinal Plants Board, MINISTRY OF AYUSH; Government of India).

\section{Extraction and preliminary fractionation}

Dried tubers were extracted with four different solvents: Hexane, ethyl acetate, methanol, and water and then methanolic extract (yield $12.5 \mathrm{~g}$ ) was further fractionated using the above-mentioned solvents to obtain four different fractions (hexane, ethyl acetate, methanol and water).

Quantitative phytochemical analysis

Estimation of total phenolic compounds

The quantitative estimation of phenolic compounds was done using the Folin-Ciocalteu reagent method of Lister and Wilson [6]. A standard curve was prepared using different concentrations of Gallic acid $(10-100 \mu \mathrm{g} / \mathrm{ml})$. The absorbance of all the test samples (extracts and fractions) was measured at $760 \mathrm{~nm}$. Total phenolic content was expressed as mg/g Gallic acid equivalent (GAE) [7]

\section{Estimation of total flavonoid content}

The flavonoid content in the extract was determined spectrophotometrically by the method of Quettier-Deleu et al. [8]. Rutin was used as the standard to make the calibration curve and the absorbance of the reaction mixture was measured at $430 \mathrm{~nm}$. The flavonoid content was expressed as $\mathrm{mg} / \mathrm{g}$ rutin equivalent (RE).

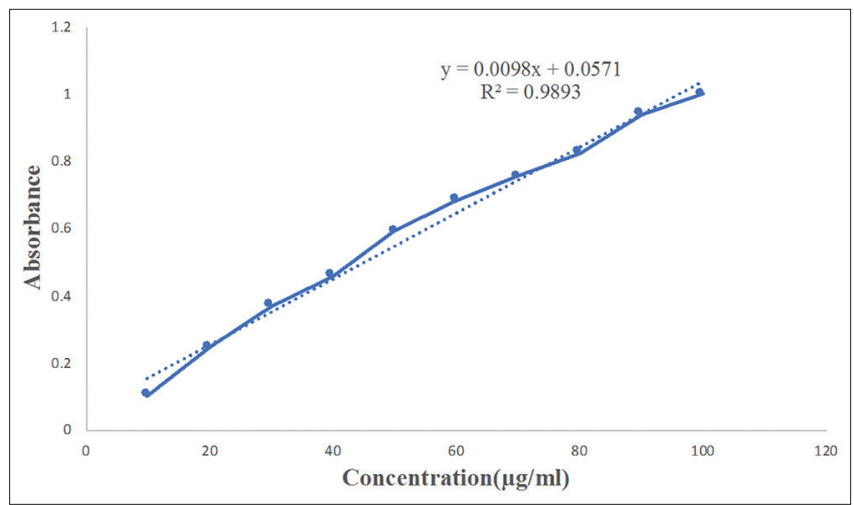

Fig. 1: Calibration curve of gallic acid 


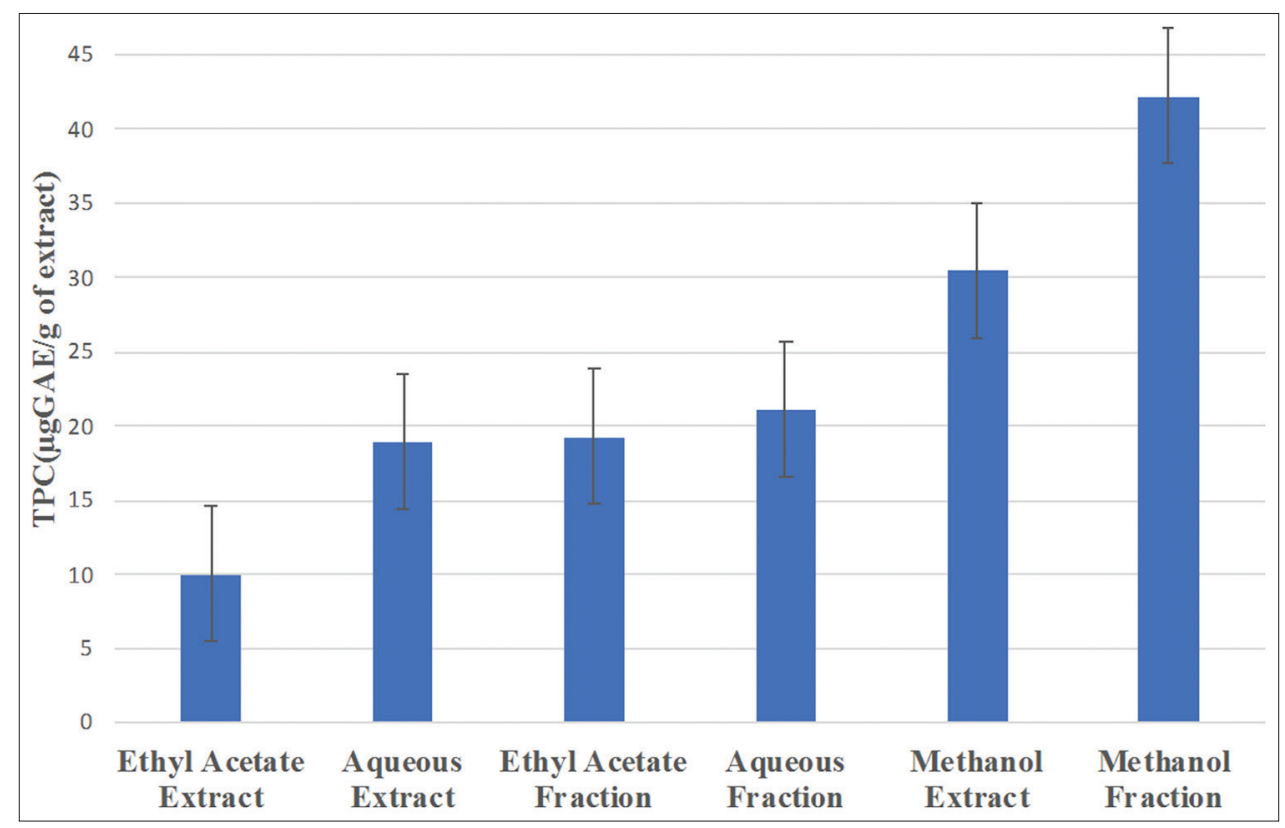

Fig. 2: Total phenolic content of different extracts and fractions of Habenaria pectinata. $*$ All the data were reported as mean \pm standard error of three replicates $(n=3)$

Free radical scavenging ability (2,2-diphenyl-1-picrylhydrazyl [DPPH])

The scavenging ability of various extracts and fractions on DPPH free radicals was estimated according to the method of Shimada et al. [9] An equal amount of methanol and DPPH served as a control. The absorbance of the test solutions was measured at $517 \mathrm{~nm}$ against a blank. The DPPH radical scavenging activity was calculated by the following equation:

$\%$ DPPH radical scavenging activity $=\left(\mathrm{A}_{0}-\mathrm{A}_{1}\right) / \mathrm{A}_{0} \times 100 \%$.

Where $A_{0}$ is the absorbance of the control reaction and $A_{1}$ is the absorbance of the sample of the tested extracts. $\mathrm{IC}_{50}$ values were also calculated for all the extracts and fractions.

\section{Reducing power ability}

The reducing power ability of methanol extract was determined by the method given by Oyaizu [10] using ascorbic acid as standard.

\section{Statistical analysis}

All the data were reported as mean \pm standard deviation of three replicates.

\section{RESULTS}

The total phenolic content of the extracts and fractions was determined using the calibration curve with different concentration of Gallic acid as $y=0.0098 x+0.0571, R^{2}=0.9893$ (Fig. 1). The methanol extract of H. pectinata was found to possess phenolic content $30.51 \pm 4.87 \mathrm{mg} / \mathrm{g}$ GAE followed by ethyl acetate extract showed $10.020 \pm 4.96 \mathrm{mg} / \mathrm{g}$ GAE and aqueous extract revealed $18.938 \pm 5.23 \mathrm{mg} / \mathrm{g}$ GAE. The methanolic fraction obtained by fractionation from the methanolic extract was found to possess phenolic content $42.244 \pm 5.6 \mathrm{mg} / \mathrm{g} \mathrm{GAE}$; ethyl acetate fraction $19.285 \pm 4.76 \mathrm{mg} / \mathrm{g} \mathrm{GAE}$ and aqueous fraction $21.122 \pm 5.21 \mathrm{mg} / \mathrm{g}$ GAE (Fig. 2).

The total flavonoid content of the extracts was determined as a rutin acid equivalent. The calibration curve with different concentrations of rutin acid was created as $y=0.0096 x+0.0065 ; R^{2}=0.9984$ (Fig. 3). The methanol extract showed a significant amount of flavonoid content $16.608 \pm 1.28 \mathrm{mg} / \mathrm{g}$ RE followed by aqueous extract revealed $10.235 \pm 0.346 \mathrm{mg} / \mathrm{g} \mathrm{RE}$ and ethyl acetate extract possess $5.208 \pm 0.49 \mathrm{mg} / \mathrm{g}$ RE (Fig. 4). The methanolic fraction showed flavonoid

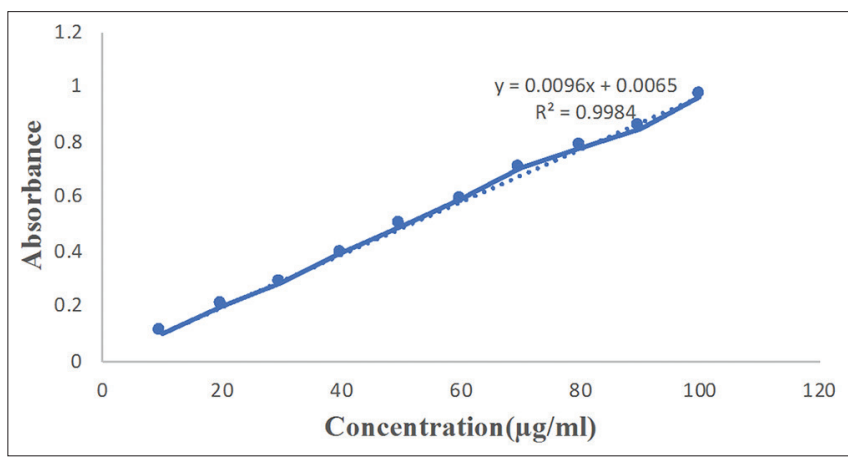

Fig. 3: Calibration curve of rutin

content $26.041 \pm 2.06 \mathrm{mg} / \mathrm{g} \mathrm{RE}$; aqueous fraction $12.625 \pm 1.23 \mathrm{mg} / \mathrm{g} \mathrm{RE}$; and ethyl acetate fraction $10.625 \pm 0.643 \mathrm{mg} / \mathrm{g} \mathrm{RE}$.

The DPPH radical scavenging activity of all extracts and fractions has been expressed in Fig. 5 in comparison with ascorbic acid as a standard. Ascorbic acid showed the lowest $\mathrm{IC}_{50}$ value of $0.586 \pm 0.014$ and maximum scavenging activity. As compared to ascorbic acid, methanolic fraction and extract were found to possess significant DPPH radical scavenging activities with an $\mathrm{IC}_{50}$ value $-0.642 \pm 0.013$ and $1.52 \pm 0.017$, respectively. The aqueous fraction showed $\mathrm{IC}_{50}$ value $0.976 \pm 0.015$ followed by ethyl acetate fraction and extract, as shown in Fig. 5.

Fig. 6 showed the reducing ability of ascorbic acid as a standard in comparison with different extracts and fractions of $\mathrm{H}$. pectinata. Among them, methanol fraction and extract exhibited higher reducing activity followed by ethyl acetate extract dependent on concentration. At the highest concentration $(1 \mathrm{mg} / \mathrm{ml})$, the reducing potential of methanol extract and a fraction was found to be $0.975 \pm 0.032$ and $0.987 \pm 0.014$, respectively, followed by ethyl acetate extract $(0.674 \pm 0.025)$ and fraction $(0.773 \pm 0.034)$ as compared with ascorbic acid $(0.687 \pm 0.013)$.

\section{DISCUSSION}

Flavonoids are globally known for free radical scavenging, antioxidative, anti-inflammatory, and anticancer activity [10]. In this study, the quantitative analysis of phenol and flavonoid 


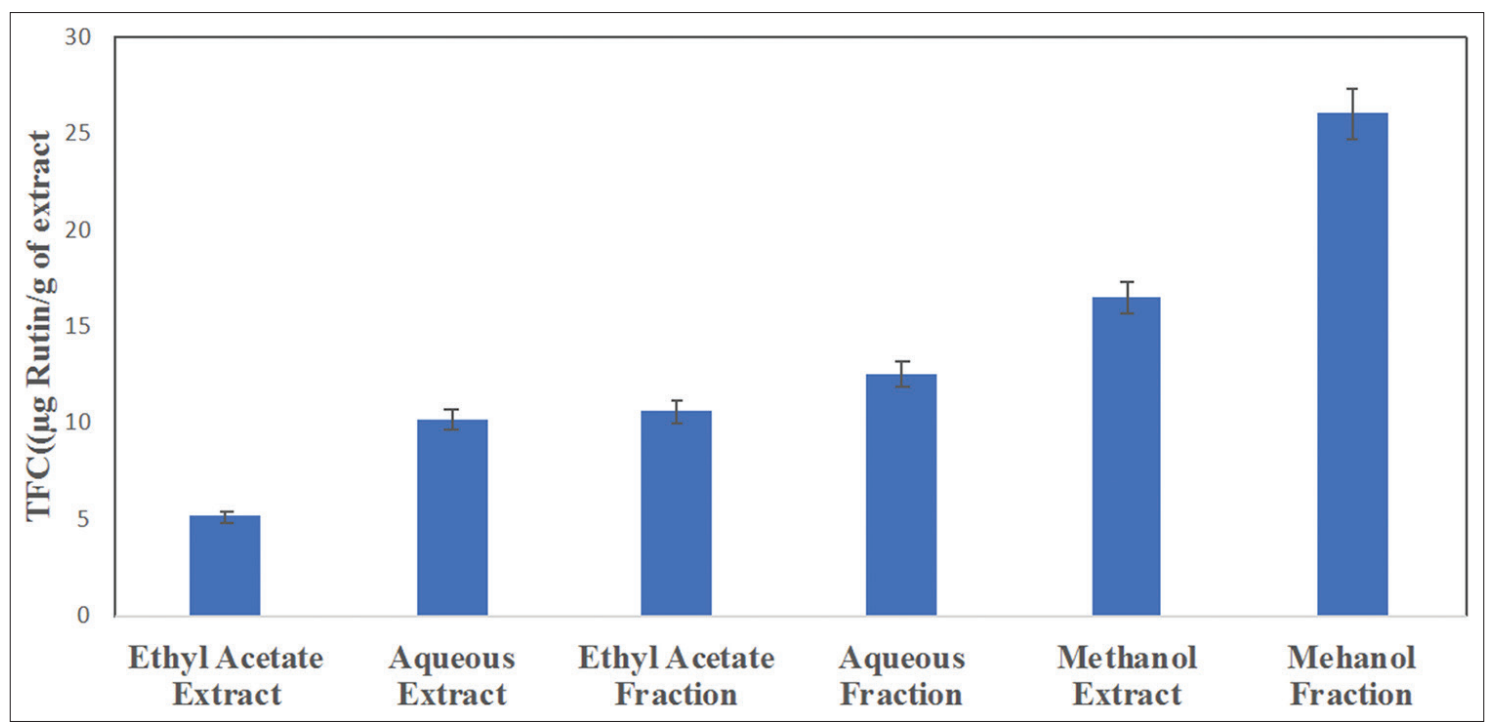

Fig. 4: Total flavonoid content of different extracts and fractions of tubers of Habenaria pectinata. *All the data were reported as mean \pm standard error of three replicates $(n=3)$

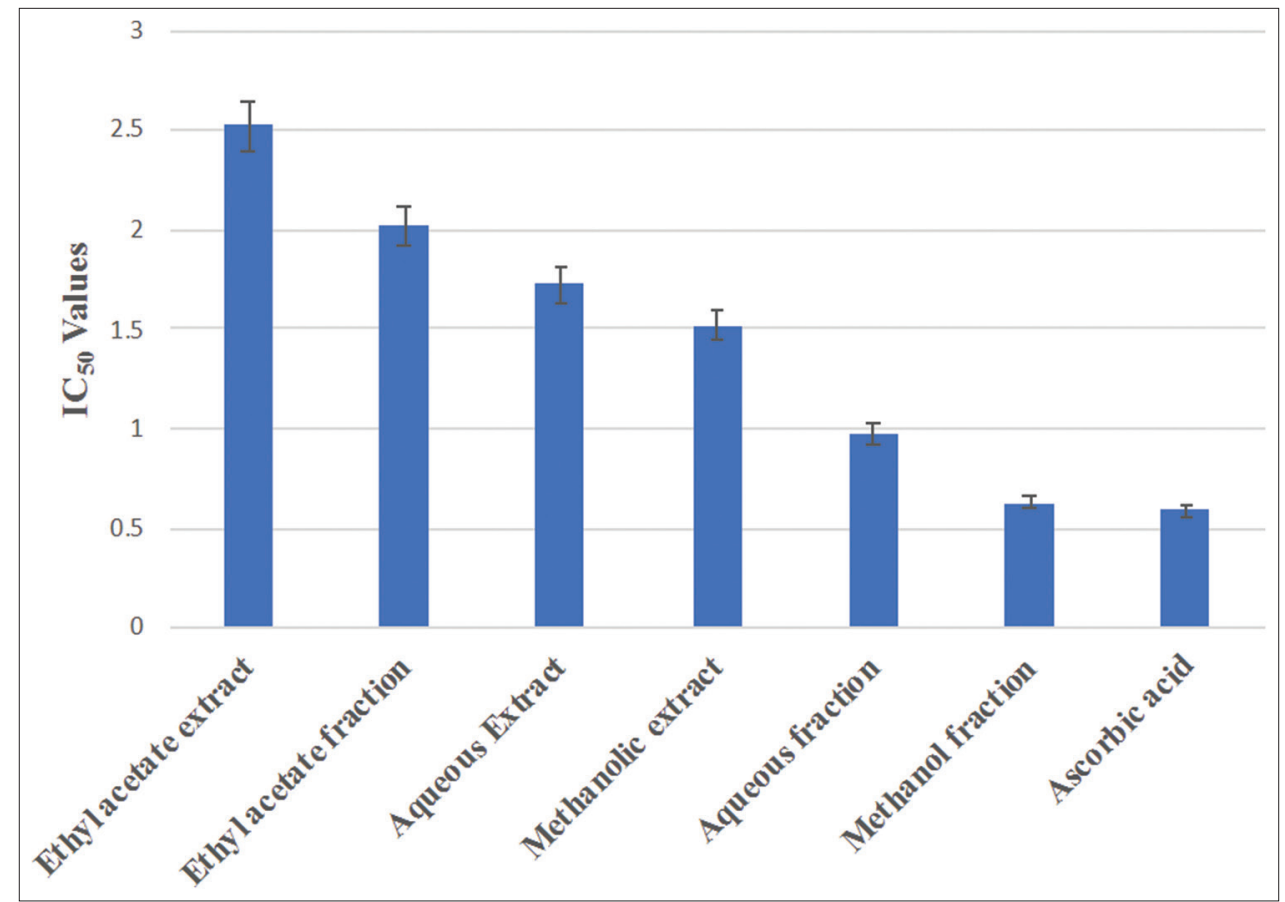

Fig. 5: 2,2-diphenyl-1-picrylhydrazyl radical scavenging activities of different extracts and fractions of tubers of Habenaria pectinata in comparison to standard ascorbic acid. *All the data were reported as mean \pm standard error of three replicates $(n=3)$

content (Figs. 2 and 4) of the extracts was performed based on the results of preliminary phytochemical investigations conducted to check the presence of phenols and flavonoids [11]. The methanol extract and fraction of H. pectinata were found to possess maximum phenolic and flavonoid content which signified its high antioxidant potential which depends on the concentration of phenols and flavonoids present in the plant [12]. This study is the first report of antioxidant potential of $H$. pectinata. The results showed the higher antioxidant potential in terms of DPPH free radical scavenging activity for methanol fraction followed by an aqueous fraction (Fig. 5). Reducing power signifies the reductive ability of antioxidants and the transformation of $\mathrm{Fe}^{+3}$ to $\mathrm{Fe}^{+2}$ in the presence of the extract [13]. Ascorbic acid showed the lowest $\mathrm{IC}_{50}$ value and maximum scavenging activity in comparison to the extracts and fractions. Several reports indicated that the phenolic content of the plant extracts had the reducing power of bioactive compounds and associated antioxidant activity [14-18]. The reducing power (Fig. 6) was found to increase with the increased concentration of extracts as well as fractions tested in this study and significant antioxidant activity was observed in the methanol extract and fraction in comparison to ascorbic acid. Our results revealed a substantial free radical scavenging as well as reducing potential of the different solvent extracts and fractions of tubers of $H$. pectinata when compared with ascorbic acid as standard. 


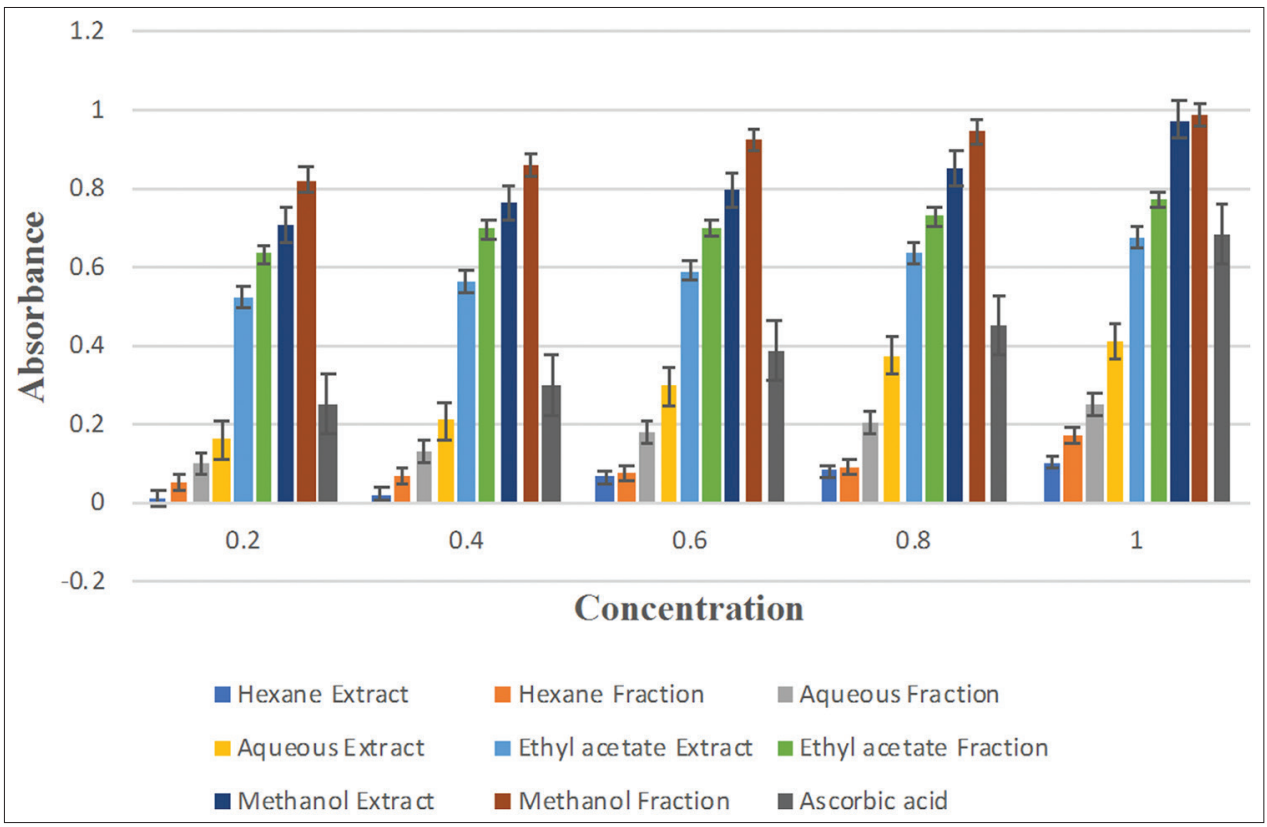

Fig. 6: Reducing powers of different extracts and fractions in comparison to ascorbic acid. *All the data were reported as mean \pm standard error of three replicates $(n=3)$

\section{CONCLUSION}

It can be assumed that the methanol extract and fraction of $H$. pectinata possess the potent antioxidant capacity in DPPH and ferric reducing antioxidant power assay methods. All other extracts and fractions also exhibited significant antioxidant potential except hexane extract in comparison to ascorbic acid standard. Thus, it may be considered as a potential biosource of antioxidants.

\section{ACKNOWLEDGMENT}

The authors are grateful to I. K. Gujral Punjab Technical University, Kapurthala, Punjab, for providing scientific support and Dr. R. K Dhawan, Director-principal, Khalsa College of Pharmacy, Amritsar, Punjab, for the encouragement to carry out this research work.

\section{AUTHORS' CONTRIBUTIONS}

The authors declare that all the authors have contributed equally to this article.

\section{CONFLICTS OF INTEREST}

The authors have no conflicts of interest to disclose.

\section{FUNDING}

This research did not receive any specific grant from funding agencies.

\section{REFERENCES}

1. Benkeblia N. Antimicrobial activity of essential oil extracts of various onions (Allium cepa) and garlic (Allium sativum). LWT-Food Sci Technol 2004;37:263-8.

2. Mitra A, Choudhury MD, Choudhury PR, Nath D, Das S, Talukdar AD. Antioxidative and free radical scavenging potentials of Cyclosorus interruptus (Willd.) H. Itô and Pronephrium nudatum (Roxb. Ex Griff.) Holttum. Asian J Pharm Clin Res 2019;12:87-94.

3. Chen X, Gale SW, Cribb PJ, Ormerod P. Flora of China. Vol. 25. Beijing, China, St. Louis: Science Press, Missouri Botanical Garden Press; 2009. p. 201-5.

4. Singh A, Duggal S. Medicinal orchids: An overview. Ethnobot Lealf 2009;3:3.

5. Rawat S, Jugran AK, Bahukhandi A, Bahuguna A, Bhatt ID, Rawal RS, et al. Anti-oxidant and anti-microbial properties of some ethnotherapeutically important medicinal plants of Indian Himalayan Region. 3 Biotech 2016;6:154.

6. Lister E, Wilson P. Measurement of Total Phenolics and ABTS Assay for Antioxidant Activity (Personal Communication). New Zealand: Crop Research Institute, Lincoln; 2001.

7. Madaan R, Bansal G, Kumar S, Sharma A. Estimation of total phenols and flavonoids in extracts of Actaea spicata roots and antioxidant activity studies. Indian J Pharm Sci 2011;73:666-9.

8. Quettier-Deleu C, Gressier B, Vasseur J, Dine T, Brunet C, Luyckx M, et al. Phenolic compounds and antioxidant activities of buckwheat (Fagopyrum esculentum Moench) hulls and flour. J Ethnopharmacol 2000;72:35-42

9. Shimada K, Fujikawa K, Yahara K, Nakamura T. Antioxidative properties of xanthan on the autoxidation of soybean oil in cyclodextrin emulsion. J Agric Food Chem 1992;40:945-8

10. Oyaizu M. Studies on products of browning reactions: Antioxidant activities of products of browning reaction prepared from glucose amine. Jpn J Nutr 1986;44:307-15.

11. Gryglewski RJ, Korbut R, Robak J, Swies J. On the mechanism of antithrombotic action of flavonoids. Biochem Pharmacol 1987;36:317-22.

12. Suja S, Mohanasundari L. Antioxidant and free radical scavenging activity of the mixture of ethanolic extracts of Alpinia speciosa and Alpinia calcarata rhizome. Int J Pharm Pharm Sci 2016;8:164-70.

13. Yamaguchi $T$, Takamura H, Matoba $T$, Terao J. HPLC method for evaluation of the free radical-scavenging activity of foods by using 1,1-diphenyl-2-picrylhydrazyl. Biosci Biotechnol Biochem 1998;62:1201-4

14. Gulcin I, Oktay M, Kirecci E, Kufrevio I. Screening of antioxidant and antimicrobial activities of anise (Pimpella anisum L.) seed extracts. Food Chem 2003;83:371-82.

15. Siddhuraju P Mohan PS, Becker K. Studies on the antioxidant activity of Indian Laburnum (Cassia fistula L): A preliminary assessment of crude extracts from stem bark, leaves. Food Chem 2002;79:61-70.

16. Gurung R. Preliminary phytochemical screening total phenol and flavonoid content of Mimosa rubicaulis and Reinwardita indica. Int $\mathrm{J}$ Pharm 2020;1:54-8.

17. Jayaraman S, Variyar EJ. Immunomodulatory, anticancer and antioxidant activities of Cyclea peltata (Lam.) Hook. F. and Thomson. Int J Pharm 2019;10:40-6.

18. Gupta R, Singh RL, Gupta A. Comparative study on the antioxidant activities of methanolic and aqueous extracts of Terminalia bellerica. Int J Curr Pharm Res 2019;6:103-10. 